\title{
ANTIFUNGAL TEDAVIDE SON GELIŞMELER
}

\section{LAST DEVELOPMENTS IN ANTIFUNGAL TREATMENT}

\section{Kaan KÜÇÜKOĞLU}

Atatürk Üniversitesi, Eczacılık Fakültesi, Farmasötik Kimya Anabilim Dalı, 25140 Erzurum, TURKEY

\section{ÖZET}

Dünyada immün sistemi tehlikede olan hasta sayısının artması nedeniyle invazif mantar enfeksiyonları artmaktadır. Bu enfeksiyonların tedavisinde 50 yıldan daha uzun bir süredir toksik etkilerine rağmen amfoterisin B deoksikolat “altın standart” olmuştur. Bununla birlikte, son 15 yll boyunca invazif mantar enfeksiyonları için yeni ve geliştirilmiş tedavi opsiyonları ortaya çıkmıştır. Son zamanlarda keşfedilen yeni triazoller ve ekinokandinler antifungal tedaviye eklenmiştir. Yeni triazol bileşikleri, vorikonazol ve posakonazol, geniş antifungal aktivite spektrumuna sahiptir. Vorikonazol invazif aspergillosis için seçimli ilaç olmuştur. Posakonazol de zigomikozis tedavisinde etkili bulunmuştur. İnvazif fungal enfeksiyonlara karşı spesifik etki mekanizmasına sahip ekinokandinler benzer aktivite spektrumu, farmakokinetik ve antifungal etkinliğe sahiptir. Bu bileşiklerin kandidemi ve invazif kandidiyaz tedavisinde etkili olduğu gösterilmiştir.

Anahtar kelimeler: Mantar enfeksiyonlart, Antifungal ajanlar, Ekinokandinler

\section{ABSTRACT}

In the world, invasive fungal infections are increasing because of rising the numbers of immunocompromised patients. For over 50 years, amphotericin B deoxycholate has been the "gold standard" in the treatment of these infections, in spite of its toxic effects. However, during the last 15 years, new and improved therapy options for invasive fungal infections have been appeared. New triazoles and the echinocandins that were recently discovered have been added to antifungal therapy. The new triazole agents,
} 
voriconazole and posaconazole, have a broad spectrum of antifungal activity. Voriconazole has become the agent of choice for invasive aspergillosis. Posaconazole appears to be effective for the treatment of zygomycosis, too. Against invasive fungal infections echinocandins with unique mechanisms of action have similar spectrum of activity, pharmacokinetics and antifungal efficacy. These agents have been shown to be effective in the treatment of candidemia and invasive candidiasis.

Key words: Fungal infections, Antifungal agents, Echinocandins

\section{GíRiş}

Son 20 yıl boyunca invazif mantar enfeksiyonu vakaları ciddi bir biçimde artış göstermiştir (1). Bu tür enfeksiyonlar, teşhisi, önlenmesi, tedavisi güç, yüksek mortalite ve morbidite oranı ile karakterize edilen olgulardır (2). İnvasif mantar enfeksiyonu için majör risk faktörleri, yoğun ve uzun süren sitotoksik kemoterapi tedavisinin neden olduğu nötropeni, yüksek dozda kortikosteroid tedavisi, kateter ve prostetik araç kullanımı, uzun süren antibiyotik tedavisi, hematopoietik gövde hücresi veya tam organ nakli, yanıklar, makrofaj disfonksiyonu ve konjenital veya kazanılmış immün yetersizliktir $(3,4,5)$. Bu faktörler göz önünde bulundurulduğunda yüksek risk altında olan bireyler, yoğun bakım ünitelerinde tedavi görenler, cerrahi hastaları, HIV/AIDS hastaları, lösemi ve lenfoma gibi hematolojik kanser türü olan kişiler ve solid tümörü olan hastalardır $(3,6)$. Solid organ, kemik iliği veya hematopoietik kök hücresi nakli geçiren hastalar veya yüksek dozda kortikosteroid tedavisi uygulanan kişiler de benzer şekilde yüksek risk altındadır (7,8). AIDS hastalığının artışı, transplantasyon hekimliğinin gelişmesi, kemoterapi tedavisi alan kanser hastalarının sayısındaki büyük artış, cerrahi müdahale geçiren, kateter uygulanan, parenteral beslenen, geniş spektrumlu antibiyotik tedavisi gören ve hemodiyaliz uygulanan hastaların sayısındaki artışlar invazif mantar enfeksiyonlarının giderek artmasında önemli rol oynamıştır (9). 1980-1987 yılları arasında invazif mantar enfeksiyonlarının neden olduğu mortalitedeki artış 3,4 kat olmuştur; ölümler ise her 100000 kişide 0.7 'den 3.4'e yükselmiştir (10). 1980 y1lında hastaneden taburcu olan her 1000 kişiden 2'sinde bu tür vakalar görülürken 1995 yılında bu rakam 1000 kişide 10.8 'e yükselmiştir $(11,12)$. HIV hastalarında en yaygın firsatçı enfeksiyon orofaringial ve özofagial kandiyazisdir (13). Ayrıca HIV hastalarının \%10 (14) - \%50'si (15) hastalığın seyri boyunca bir özofagial kandiyazis enfeksiyonu geçirmektedir. Allogeneik hematopoietik gövde hücresi nakli olmuş hastaların \%15'inde invazif mantar enfeksiyonu görülmektedir (16). Akciğer nakli gerçekleştirilen hastalarda bu enfeksiyon oranı \%20'dir (3). Gelişmiş ülkelerde AIDS hastalarının \%60’1 Pneumocystis carinii pnömonisine, \%20'si ise özofagial kandiyazise 
yakalanmaktadır (17). Güneydoğu Asya'daki AIDS hastalarının yaklaşık \%30'unda ise Penicillium marneffei'nin etken olduğu enfeksiyonlar mevcuttur (18).

Görülen bu enfeksiyonların çoğu Candida ve Aspergillus türlerinden kaynaklanmaktadır; ancak Fusarium türleri, Cryptococcus neoformans, Pseudoallescheria boydii gibi küfler ve Zigomisetler de giderek artan sayıda vakada etken olarak ortaya çıkmaktadır (19). ABD'de Candida türleri hastane enfeksiyonlarına neden olan en yaygın dördüncü patojendir (\%8) ve en yüksek ölüm oranına (\%40) sahiptir (2). Candida albicans, sistemik enfeksiyonların yaklaşık $\% 50$ 'sinden sorumlu en yaygın enfeksiyon etkeni olan Candida türüdür $(9,11,12)$. Aspergillus türleri daha az yaygın enfeksiyon etkeni olmalarına karşın, bütün nozokomiyal mantar enfeksiyonlarının yaklaşık \%4-5'inden sorumludur. Bağışıklık sistemi zayıf olan hastalarda hayatı tehdit edici invazif mikozisin önemli bir nedeni Aspergillus türleridir (20). Bu mantarlar, organ nakli veya hematolojik kanser hastalarının bakımlarının yapıldığı birçok bakım ünitesinde, hastaları \%30'unda morbidite ve mortalite nedenidir (6). İnvazif aspergillosis enfeksiyonlarında yoğun antifungal tedaviye rağmen ölüm oranı \%85'e ulaşmaktadır (20).

Tablo 1. Majör antifungal ilaç sınıflarının keşfi.

\begin{tabular}{|c|c|c|c|c|c|c|}
\hline & Poliketitler & Polienler & Azoller & Pirimidinler & Ekinokandinler & Allilaminler \\
\hline $\mathbf{1 9 5 0}$ ler & Griseofulvin & $\begin{array}{c}\text { Amfoterisin } \\
\text { B } \\
\text { Nistatin }\end{array}$ & Klormidazol & & & \\
\hline $\mathbf{1 9 7 0}$ ler & & & $\begin{array}{c}\text { Topikal } \\
\text { imidazoller }\end{array}$ & Flusitozin & & \\
\hline $\mathbf{1 9 8 0}$ ler & & $\begin{array}{c}\text { Sistemik } \\
\text { imidazoller }\end{array}$ & & Cilofungin & \\
\hline $\mathbf{1 9 9 0}$ lar & & & $\begin{array}{c}\text { Sistemik } \\
\text { triazoller }\end{array}$ & & $\begin{array}{c}\text { Naftifin } \\
\text { Terbinafin }\end{array}$ \\
\hline
\end{tabular}

*Verilen tarihler, ilaçların in vitro antifungal aktivitelerinin bulunmasından çok, klinik denemelere başlanma tarihlerini göstermektedir (25).

Son zamanlara kadar invazif mantar enfeksiyonlarının tedavisi için 3 antifungal ilaç sınıfı mevcuttu. Bunlar polienler (Amfoterisin B), azoller (Ketokonazol, itrakonazol, flukonazol) ve flusitozindi (3). Bu ilaçlardan amfoterisin B geniş bir aktivite spektrumuna sahiptir. Değişik lipit formülasyonları halinde (Örneğin, amfoterisin B deoksikolat) bu tür enfeksiyonların tedavisinde uzun yıllardır kullanılagelmiş ve bu yüzden "altın standart" olarak adlandırılmıştır (21). Ancak bu ilacın kullanımına başta nefrotoksisite olmak üzere şiddetli yan etkiler eşlik etmiştir (22). 
1990'ların başında yeni triazol türevlerinin keşfi farklı tedavi olanakları sunmuştur (21). Bu ilaçların tolere edilebilme profilleri iyileştirilmiştir; ancak yoğun kullanımları, duyarlı suşlarda rezistansın ortaya çıkışına yol açmıştır (22). Bu sebeple farmakolojik özellikleri ve rezistans profili iyileştirilmiş, aktivite spektrumu genişletilmiş, etkinliği artırılmış ve daha iyi tolere edilebilen yeni antifungal ilaçlara gereksinim vardır. Bu antifungal ilaçların keşfi için iki yaklaşım üzerinde durulmuştur: i) İlk yaklaşım, varolan antifungal bileşiklerin formülasyon ve/veya dağılım sistemlerinin modifikasyonudur. Bu yaklaşımın uygulanması ile amfoterisin $\mathrm{B}$ nin değişik lipit formülasyonları ve intravenöz itrakonazol kullanıma girmiştir. ii) Diğer yaklaşım ise mevcut ilaçlardan farklı etki mekanizmasına sahip, mantarın farklı yapısal komponentlerini hedefleyen ilaçlar geliştirmektir. Böylece ekinokandin grubu ilaçlar ortaya çıkmıştır (23). Ayrıca varolan azol grubu ilaçların yapısında, aktivite spektrumları genişleyecek biçimde kimyasal modifikasyonlar yapılmış ve yeni triazol türevi ilaçlar elde edilmiştir (24). Son 6 yılda yeni geliştirilmiş iki triazol (Vorikonazol ve posakonazol) ve üç ekinokandin türevi (Kaspofungin, mikafungin ve anidulafungin) ilaç tedavide kullanım için onay almıştır. $\mathrm{Bu}$ antifungallerin birçoğunun daha az toksik olduğu ve bazı durumlarda amfoterisin B'ye göre daha etkili olduğu kanıtlanmıştır (21).

\section{1. İKINCİ JENERASYON TRIAZOLLER}

\subsection{Vorikonazol}

Triazol türevi yeni bir antifungal ilaç olan vorikonazol, FDA tarafından 2002 tarihinde onay almıştır. Yapısal olarak flukonazole benzeyen bir ilaçtır. Flukonazolde mevcut olan triazol kısmı floropirimidin grubu ile değiştirilmiş ve propanol zincirine bir metil grubu eklenerek vorikonazol elde edilmiştir (26).

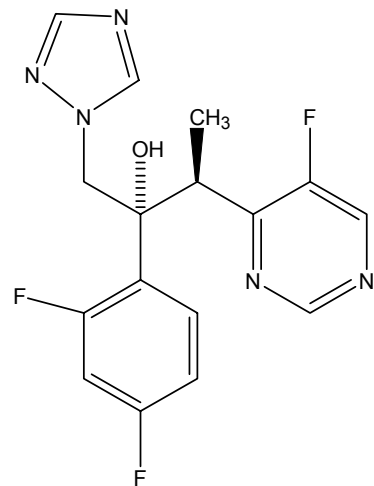

VORIKONAZOL

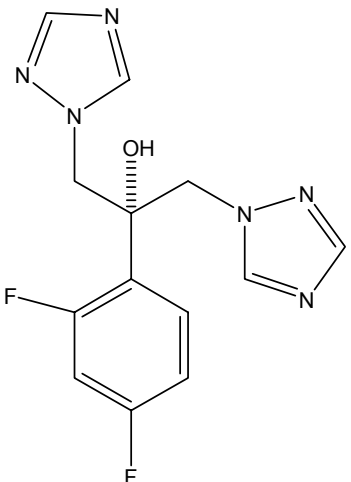

FLUKONAZOL

Şekil 1. Vorikonazol ve flukonazolün yapısal formülleri 
Vorikonazol, mantar membranlarının bileşeni olan ergosterolün sentezini bloke eden bir enzim inhibitörüdür. Dolayısıyla mantarın gelişimini inhibe eder. Flukonazol ve itrakonazol gibi

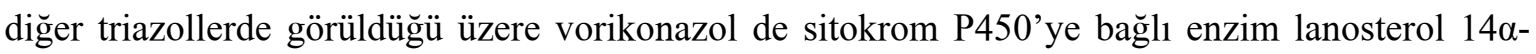
demetilazın aktif yöresine bağlanır $(27,28)$. Bu inhibisyon, ortamda ergosterol miktarının

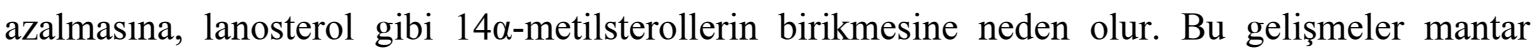
membranının bütünlük ve fonksiyonunu etkiler (29).

Vorikonazol, flukonazole göre daha güçlü bir CYP51 inhibitörüdür. Flukonazole rezistan $C$. albicans ve C. krusei dahil Candida spp., itrakonazol ve amfoterisin B ye dirençli Aspergillus fumigatus dahil Aspergillus spp., Scedosporium spp. ve Fusarium spp. gibi patojenlere karşı in vitro aktiviteye sahip, geniş spektrumlu bir antifungaldir (30). Böylece invazif aspergillosis, özofageal kandidiyaz, non-nötropenik hastalardaki kandidemi, derinin yaygın Candida enfeksiyonları, karın, böbrek, mesane duvarı ve yaralarında gelişen enfeksiyonlarda kullanım alanı bulmuştur (31). Vorikonazol kan-beyin engelini önemli ölçüde geçer. Bu geçişin moleküler mekanizması henüz bilinmemektedir. Klinik olarak merkezi sinir sisteminde inatçı fungal enfeksiyonu olan hastaların, vorikonazol ile başarılı bir şekilde tedavilerini gösteren bazı raporlar mevcuttur (32,33,34,35,36). Vorikonazolün, Aspergillus (37) ve Scedosporium spp. (38) nin etkeni olduğu kemik enfeksiyonları, Aspergillus endophthalmitis (39) hastalığı ve Pseudallescheria boydii (34) ve Aspergillus spp. (33) tarafından oluşturulan santral sinir sistemi enfeksiyonlarının tedavisinde başarılı kullanımı tanımlanmıştır.

Vorikonazol, invazif aspergillozisin primer tedavisindeki değerini giderek artırmaktadır $(40,41)$ ve bu enfeksiyonlarda seçimli ilaç haline gelmektedir. Amfoterisin B'ye doğal olarak dirençli Aspergillus terreus enfeksiyonlarının tedavisi için de seçimli ilaçtır (42). FDA tarafından bu endikasyonu onaylanmamış olmasına rağmen nötropenik hastalardaki ateşin ampirik tedavisi için sıklıkla kullanılır (43). Yapılan in vitro çalışma sonuçları, bileşiğin, Histoplasma capsulatum, Blastomyces dermatitidis ve Coccidioides immitis'e karşı da aktif olduğunu göstermiştir ve benzer sonuçlar in vivo olarak da elde edilmiştir (44). İlaç, Mucor ve Rhizopus gibi Zigomisetlere karş1 aktif değildir. Profilaktik olarak vorikonazol alan hastalarda Zigomisetlerden kaynaklanan enfeksiyonların görüldüğü rapor edilmiştir (45).

Vorikonazol, intravenöz ve oral yoldan kullanılabilir. İntravenöz yoldan verildiğinde ilk gün yükleme dozu olarak her 12 saatte bir $6 \mathrm{mg} / \mathrm{kg}$ dozunda verilir; sonra her 12 saatte bir $4 \mathrm{mg} / \mathrm{kg}$ dozunda uygulanır. Oral yoldan ise ilk gün her 12 saatte bir $200 \mathrm{mg}$ veya $400 \mathrm{mg}$ kullanılır; sonra vücut ağırlığına bağlı olarak her 12 saatte bir $100 \mathrm{mg}$ veya $200 \mathrm{mg}$ dozunda uygulanır. Herhangi bir ögünden önce veya sonra alınabilir (46) ve absorbsiyonu midedeki pH değişikliklerinden 
etkilenmez. Aslında serum düzeyleri ve vücut ağırlığına göre ayarlanan doz arasında önemli bir ilişki saptanamamıştır. Bu nedenle yetişkin hastalarda belli bir dozda kullanımı mümkündür (47).

Vorikonazolün biyoyararlanımı \%90 oranındadır (48). Sistemik olarak verilen vorikonazol gözde terapötik konsantrasyonlara erişmektedir. $\mathrm{Bu}$ durum, vitröz enfeksiyonlarda uygulanan intravitreal enjeksiyonlara veya keratitte uygulanan topik uygulamaya bir alternatif oluşturur. Fusarium keratitisli hastalardan elde edilen veriler, sistemik tedaviye topik vorikonazolün eklenmesinin yararlı bir etki sağlayacağını göstermektedir $(49,50)$. Vorikonazol ile tedavi edilen kemik aspergillosisli 20 hastadan 11'inde olumlu sonuçlar rapor edilmiştir. Bu da ilacın kemik dokusuna iyi difüze olduğunu göstermektedir (37).

Vorikonazol, karaciğerde metabolizasyona uğrar. Yapılan bir çalışmada idrar ve feçeste değişmeden saptanan vorikonazol miktarı sadece \%2 olarak saptanmıştır; bu ilacın yoğun bir şekilde metabolizasyona uğradığının göstergesidir. Vorikonazolün 3 adet majör metaboliti belirlenmiştir. UK-121,265 olarak adlandırılan majör metabolit, floropirimidin halkasının Noksidasyonu sonucu oluşur. Floropirimidin halkasının hidroksilasyonu ve metil hidroksilasyonunu takiben glukuronit konjugasyonu ile ortaya çıkan metabolitler diğer metabolizma ürünleridir. UK121,265 in vitro ortamda ana ilaca göre 100 kat daha az antifungal aktiviteye sahiptir (51). Karaciğer mikrozomlarında UK-121,265 metabolitinin oluşumu, sitokrom P450 (CYP) ailesine ait izoenzimler CYP3A4, CYP2C19 ve daha etkili olan CYP2C9 enzimleri aracilığı ile gerçekleşmektedir (52). Verilen vorikonazol dozunun büyük çoğunluğu (\%98) metabolitleri halinde olmak üzere 48 saat içerisinde atılır. Bir intravenöz doz vorikonazolün \%76,9'u ve bir oral doz vorikonazolün de \%79,8'i böbrek yolu ile itrah edilir. Kalan yaklaşık \%20'lik kısım da feçes ile atılır (51). İlacın atılımı böbrek yetmezliği durumlarından etkilenmez. Bununla birlikte, vorikonazolün intravenöz formülasyonu böbreklerce salgilanan sülfobutil eter $\beta$-siklodekstrin sodyum içerisinde çözünme özelliği gösterir. Bu durum, böbrek yetersizliği durumlarında doz ayarlamasını gerekli k1lar (53). Bu nedenle bu tür durumlarda ilacın oral formunun kullanılması önerilir. Ayrıca peritoneal diyalize giren hastalardan elde edilen veriler, bu hastalarda doz ayarlamasının gerekli olmadığını göstermiştir (54). Vorikonazolün yoğun metabolizasyonu dikkate alındığında kronik karaciğer hastalığı olan hastalarda doz azaltılması önerilir. Sirozlu hastalarda (Child-Pugh sınıfı C olanlar) kullanım ise kontrendikedir. Vorikonazol çoğunlukla CYP3A4 ve CYP2C19 tarafindan yoğun bir biçimde metabolize edildiği için bu enzim inhibitörleri veya stimülatörlerinin vorikonazol kinetiklerini etkilemesi beklenmelidir (55). Siklosporin, rifampisin, fenitoin, karbamazepin, ritonavir, uzun etkili barbitüratlar ve sirolimus alan hastalarda vorikonazol kullanımından kaçınılmalıdır (56). 
Vorikonazol birkaç yan etki gösterebilir. En sık görülenler transaminaz enzim düzeylerinde hafif yükselme ve görme ile ilgili rahatsızlıklar, kızarıklıklar ve gastrointestinal semptomlardır (44). Enzimlerde görülen yükselme reversibldır. Görme ile ilgili semptomlar oldukça geneldir (\%14-44) ve fotofobi, bulanık görme ve renk ayırımının değişmesi şeklinde ortaya çıkar. Bu etkiler nedeniyle ilacin kesilmesi ise nadirdir (45).

\subsection{Posakonazol}

İlk olarak Avrupa'da 2005 yılında kullanılmaya başlanmış, 2006'da FDA tarafından onaylanmıştır (56). Yapısal olarak itrakonazole benzeyen bir ilaçtır. İtrakonazolde fenil halkası üzerinde bulunan klor sübstitüentleri flor ve dioksolan halkası da furan ile yer değiştirmiştir. Ayrıca posakonazolde triazol grubu üzerinde bulunan alkil zincirinde bir hidroksil grubu mevcuttur (57).

Posakonazol de diğer triazoller gibi, lanosterol $14 \alpha$-demetilaz enzimini inhibe ederek etki gösterir (56). Geniş spektrumlu antifungal bir ilaçtır. Diğer azollere karşı dirençli Candida spp. (58), Cryptococcus neoformans (59), Aspergillus spp. (60), Rhizopus spp. (61), Bacillus dermatitidis, Coccidioides immitis, Histoplasma capsulatum ile diğer firsatçı filamentöz ve dimorfik mantarlara etkilidir (62). Trichosporon türlerine karş1 in vitro fungistatik aktiviteye sahiptir $(63,64)$. Posakonazol, Aspergillus türlerine karşı amfoterisin B'den 4-16 defa daha aktiftir (61). Ancak Aspergillus türlerinin ilaca duyarlılı̆g 1 farkl11ık gösterir. Posakonazol, amfoterisin B'ye dirençli Aspergillus terreus'a karşı in vitro ortamda aktiftir $(42,65,66)$. Aspergillus niger ise ilaca daha az duyarlıdır (63). Posakonazol, Fusarium türlerine karş1 da aktiftir (67); ancak fungistatik aktivitesi değişkendir ve türe bağlıdır (63). Posakonazol, Zigomiset türlerine karşı farklı aktivite göstermektedir. Zigomikoziste amfoterisin B'ye göre daha az aktif, vorikonazol ve flukonazolden daha aktif, itrakonazole göre ise biraz daha aktiftir (68). Posakonazol in vitro ortamda Exophiala jeanselmei ve Rhinocladiella türlerine karş1 aktivite gösterir (69). Posakonazol, orofaringial kandiyazisde ilk tercih ilaç olarak ve diğer antifungal ilaçlara direnç gösteren yetişkin hastalardaki invazif aspergillosis, fusariosis, kromoblastomikozis, mycetoma ve koksidioidomikozis enfeksiyonlarının tedavisi için onaylanmış bir antifungaldir (56). Posakonazol, orofaringeal kandidiyaz tedavisinde flukonazol kadar etkilidir (70). Aspergillus türlerine karşı etkili bir ilaç olduğundan, bağışıklık sistemi iyice baskılanmış hastalarda invazif fungal hastalıktan ölümü önlemede flukonazole üstündür $(71,72)$. Posakonazolün invazif fusarioziste \%48 (73), kriptokokal menenjit ve diğer santral sinir sistemi mantar enfeksiyonlarında \%50 oranında başarılı olduğu (74) ve koksidioidomikoziste (75) kurtarıcı tedavi olarak etkili olduğu gösterilmiştir. 


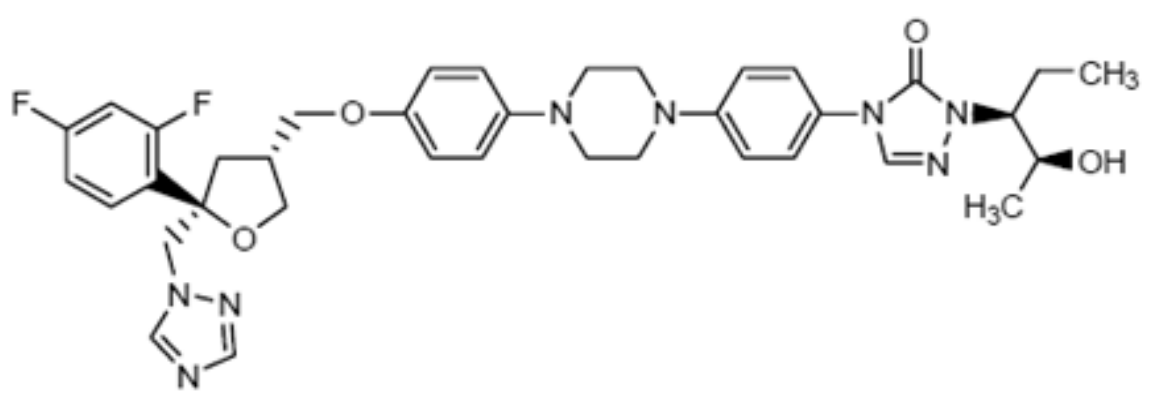

POSAKONAZOL

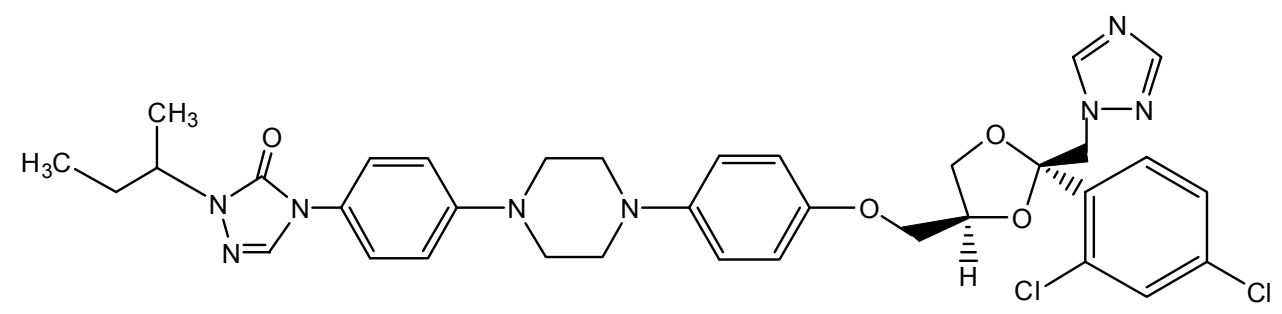

ITRAKONAZOL

Posakonazol, genellikle, yaklaşık 7 gün boyunca günde 4 defa $200 \mathrm{mg}$ dozunda verilir (yükleme dozu); sonra günde 2 defa $400 \mathrm{mg}$ dozunda uygulanır (İdame tedavisi)(76). Sadece oral yoldan kullanılabilmesi majör dezavantajıdır; çünkü ciddi vakalarda intravenöz olarak kullanılması mümkün değildir (77). Sağlıklı gönüllülerde posakonazol absorbsiyonunun midedeki pH değişikliklerinden etkilenmediği saptanmıştır (78).

Posakonazolün mide boş iken biyoyararlanımı \%8-47 iken yağ içeriği yüksek bir öğünden sonra alındığında biyoyararlanımı \%400 artmaktadır. Doza bağlı olarak uzun bir eliminasyon yarı ömrüne sahiptir $(78,79,80)$. Dokulara yaygın bir biçimde dağılır $(78,80)$. İlacın metabolizasyonu esasen karaciğerde glukuronidasyona uğrama şeklinde gerçekleşir. Metabolitleri inaktiftir. Bu parçalanma ürünleri \%70,6-77 oranında feçes içerisine atılır. Renal atılım, minör eliminasyon yolağ1 olduğundan idrarda metabolitlerin bulunma oranı daha düşüktür $(80,81)$. Posakonazolün karaciğerde metabolize olması böbrek fonksiyonu bozulmuş hastalarda amfoterisin B'ye uygun bir alternatif olmasını sağlamaktadır. Ayrıca posakonazol hemodiyaliz ile uzaklaştırılmaz (82). Beyin omurilik sıvısı içerisine penetrasyonu zayıf olmasına karşın (83), santral sinir sistemindeki mantar enfeksiyonlarında etkili olduğunu gösteren raporlar mevcuttur $(74,84)$. Posakonazol, vorikonazole göre daha dar bir etkileşim profiline sahiptir. Ritonavir, indinavir, siklosporin ve takrolimus dozu da posakonazol ile birlikte alım söz konusu ise azaltılması gerekli olabilir (85). Posakonazolün kinidin, pimozit, bepridil, sertindol, dofetilit ve halofantrin ile aynı anda kullanımı potansiyel etkileşmeye neden olabilir (86). 
Posakonazol ile tedavi edilen hastaların en fazla \%43'ünde yan etkiler rapor edilmiştir ve bu yan etkiler tedavinin ilk 6 ayında yaygın olarak görülmüştür (75). En sık görülen yan etkiler mide bulantısı ve kusma gibi gastrointestinal şikayetler, baş ağrısı, abdominal ağrı ve diyaredir (87). Karaciğer enzim düzeylerinde yükselme de görülebilir (88). Bu yan etkilere rağmen, posakonazol tedavisi pediatrik ve yaşlı hastalarda iyi tolere edilmiştir. Tedavinin kesilmesi nadirdir (89).

\subsection{Ravukonazol}

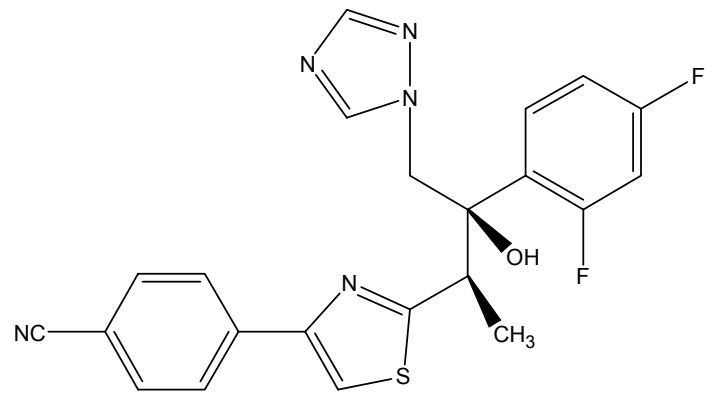

Şekil 3. Ravukonazolün kimyasal yapısı

Halen Faz II klinik deneme aşamasında araştırılan bir triazol türevidir. Flukonazole dirençli suşlar, Candida spp. , C. neoformans ve diğer maya türlerini içeren geniş bir mantar grubuna karş1 in vitro ortamda aktivitesinin yüksek olduğu bulunmuştur (90,91). Fusarium, Scedosporium prolificans ve bazı Mucorales türlerine karşı ise aktif değildir. Zigomisetlere karşı inhibitör aktiviteye sahiptir. Aspergillus spp.'ye karşı ise son derece aktiftir (92). İnvazif fungal enfeksiyonların tedavisi için ravukonazol kullanılarak insanlarda yapılmış herhangi bir çalışma şimdiye kadar mevcut değildir. Ravukonazol, şu anda sadece oral yoldan alımı araştırılan bir bileşiktir. Ayakta tedavi için kendisini çekici hale getiren 100 saatten fazla uzun bir yarı ömüre sahiptir (93).

\section{EKİNOKANDİN TÜREVİ ILAÇLAR}

En yeni antifungal ilaç sınıfı olan ekinokandinler, siklopentamin ürünleri olan amfifilik büyük lipopeptitlerdir. Zalerion arboricola veya Aspergillus nidulans var. echinulatus gibi bazı mantarların fermantasyonu sırasında oluşurlar (56). Etki mekanizmaları diğer antifungallerden farklıdır. Candida spp. ve Aspergillus spp. gibi birçok patojenik mantarın hücre duvarının önemli bir biyopolimeri olan (1,3)- $\beta$-D-glukanın sentezini sağlayan $(1,3)-\beta$-D-glukan sentaz enzimini inhibe ederler. İnhibisyon, hücre duvarı gelişmesini durdurur; bu da ozmotik değişkenlik ve duyarlı maya hücrelerinin ölümü ile sonuçlanır (94). C. neoformans ve B. dermatitidis farklı glukan polimer kompozisyonuna sahip oldukları için ekinokandinlere dirençlidir. $(1,3)-\beta$-D-glukan sentaz 
enzimi memeli hücrelerinde bulunmaz; bu yüzden ekinokandinlerin insana toksisiteleri minimaldir. Mevcut 3 ilaç da suda çözünebilme özelliği gösterir ve sadece intravenöz formülasyona sahiptir (56).

\subsection{Kaspofungin}

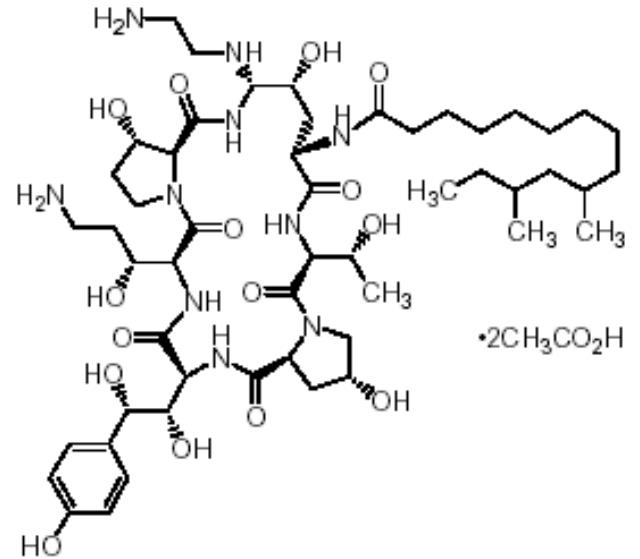

Şekil 4. Kaspofungin yapısı

Diğer antifungal tedavilere dirençli invazif aspergillozis tedavisinde kullanılmak üzere FDA tarafından 2001 yılında onaylanmıştır. Daha sonra Candida spp.'nin etkeni olduğu özofagial kandiyazis, intra-abdominal apseler, peritonit ve plevra boşluğu enfeksiyonları, kandidemi tedavisi ve nötropenili hastalarda orijini bilinmeyen ateşin ampirik tedavisi için de onay almıştır (56). Yapılan in vitro ve in vivo çalışmalar, ilacın, Aspergillus spp.' ye karşı fungistatik, birçok Candida spp.' ye karşı fungisit olduğunu göstermiştir (95). Bununla birlikte, C. parapsilosis, C. glabrata ve C. albicans'ın bu ilaca dirençli bazı suşları olduğunu gösteren bazı raporlar mevcuttur $(96,97,98)$. Pneumocystis carinii, Coccidioides immitis, Scedosporium spp. ve Paecilomyces variotii'ye karş1 aktivitesi ise daha azdır (95). Trichosporon spp., Fusarium spp., Sporothrix schenckii ve Zigomisetlere karşı aktiviteye sahip değildir $(99,100)$. İnvazif Candida enfeksiyonlarının tedavisinde kaspofungin ve amfoterisin B'nin karşılaştırıldığı bir çalışmada ilaçların etkinlikleri eşdeğer bulunmuş, kaspofunginin daha iyi tolere edildiği saptanmıştır (101). Ateşli nötropenik hastalarda ampirik kullanım için kaspofungin ile lipozomal amfoterisin B'nin karşılaştırıldığı bir çalışmada, kaspofunginin daha iyi tolere edildiği, daha az yan etki gösterdiği, fungal enfeksiyonları önlemede lipozomal amfoterisin B kadar etkili olduğu gösterilmiştir. Ayrıca temel fungal enfeksiyonları tedavi etmede lipozomal amfoterisin B’ye üstünlük sağladığı gözlenmiştir (102). Kaspofungin her ne kadar orofaringial ve özofagial kandiyazis tedavisinde lisanslı olmasa da yapılan klinik denemeler ilacın bu olgularda amfoterisin B kadar etkili olduğunu ve daha iyi tolere edildiğini göstermiştir $(103,104)$. 
Kaspofungin ilk gün bir defada $70 \mathrm{mg}$ dozunda uygulanır. İdame dozu ise hastanın ağırlığına göre belirlenir. $80 \mathrm{~kg}$ 'nn üzerindeki hastalar günde $70 \mathrm{mg}$, altındaki hastalar ise günde $50 \mathrm{mg}$ 'lık doz alarak tedaviyi sürdürür (95).

Kaspofungin başlıca karaciğerde metabolizasyona uğrar. Metabolizasyon yavaş hidroliz ve $\mathrm{N}$-asetilasyon yolu ile gerçekleşir. Ayrıca spontan degredasyon ile de metabolizasyon olur $(95,105)$. İdrara \%41 oranında metaboliti halinde ve \%1-9 oranında değişmemiş ilaç olarak atılır. Feçeste ise $\% 35$ oranında metaboliti halinde saptanmıştır (106). Orta derecede hepatik yetmezliği olan hastalarda yükleme dozunu takiben uygulanacak günlük bakım dozu 35 mg'a düşürülmelidir. Böbrek yetmezliği olan hastalarda ise doz ayarlamasına gerek yoktur. Ayrıca kaspofungin peritoneal diyaliz ile uzaklaştırılamayan bir ilaçtır (107). Kaspofungin sitokrom P450 sisteminin kötü bir sübstratı olduğu için çok sayıda ilaç ile etkileşmez. Efavirenz, karbamazepin, fenitoin, fenobarbital ve deksametazon ile aynı anda alındığında kaspofunginin etkinliği azalabilir. Rifampisin ise kaspofungin seviyesinde artma veya azalmaya yol açabilir (108). Kaspofungin takrolimusun serum düzeylerini $\% 20$ oranında azaltır. Siklosporin ile birlikte verildiğinde siklosporinin plazma konsantrasyonu \%35 oranında artar; bu duruma karaciğer fonksiyonunda geçici anormallikler eşlik eder (109).

Kaspofungin nefrotoksisite göstermez. Baş ağrısı en çok rastlanan yan etkisidir. Diğer yan etkiler, ateş, bulantı, kaşıntı, infüzyon yöresinde flebit ve hepatik enzim seviyelerinin reversibl yükselmesidir (110).

\subsection{Mikafungin}

FDA tarafindan 2005 yılında özofageal kandidiyaz tedavisi ve gövde hücresi transplantasyonu geçirmiş hastalarda profilaksi için onaylanmıştır. Genel olarak kaspofungin ile aynı antifungal aktivite spektrumuna sahiptir (56). Yapılan çalışmalarda, hem HIV pozitif hem de HIV negatif hastalardaki özofageal kandidiyaz tedavisinde mikafunginin flukonazol kadar etkili olduğu gösterilmiştir (111). Kandidemi tedavisinde mikafungin kullanılarak yapılan bir diğer çalışmada yanıt oranı \%83,2 olarak bulunmuştur (112). Gövde hücresi transplantasyonu geçirmiş hastalarda profilaksi amacıyla kullanımı flukonazol ile karşılaştırıldığında, fungal enfeksiyonların önlenmesinde mikafunginin flukonazolden daha etkili olduğu gösterilmiştir. Mikafungin alan hastalarda başarı oranı \%80'e ulaşırken flukonazol alan hastalarda bu oran \%73'te kalmıştır. Mikafungin alan grupta daha az Aspergillus enfeksiyonu gözlenmiştir (113). İnvazif aspergillosis gelişmiş lösemili hastalarda mikafungin tedavisinin başarılı olduğunu gösteren birkaç çalışma da mevcuttur $(114,115,116)$. 


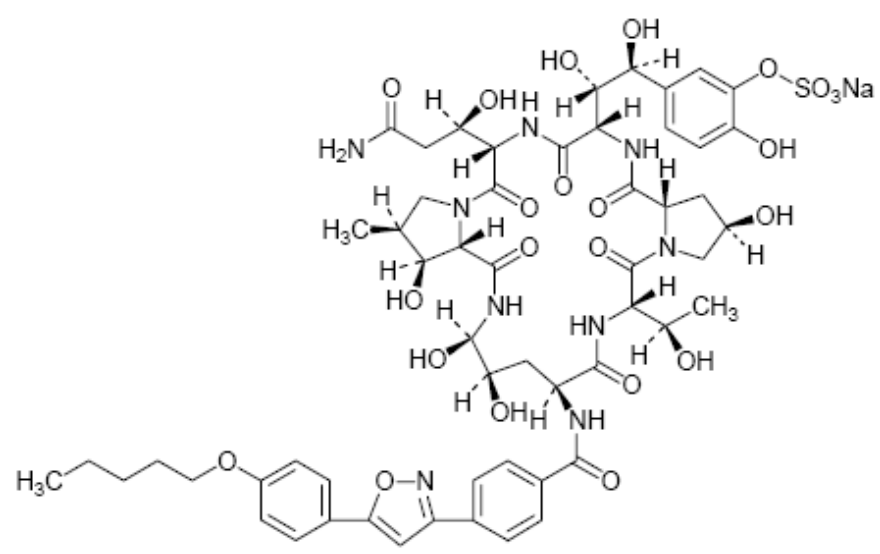

Şekil 5. Mikafunginin kimyasal yapısı

Mikafungin özofageal kandidiyazlı hastalarda günde $150 \mathrm{mg}$, gövde hücresi transplantasyonu geçirmiş hastalarda ise günde $50 \mathrm{mg}$ dozunda kullanılır (106).

Mikafungin karaciğerde metabolize edilen bir ilaçtır (118). Burada dikkat çekici olan nokta, mikafunginin antifungal özellik gösteren 2 metabolite sahip olmasıdır. $\mathrm{Bu}$ metabolitler, safra içerisine yavaşça itrah edilir (95). İlacın \%1'den daha az bir kısmı ise idrarda değişmemiş halde bulunmuştur. Kreatinin klerensi $15 \mathrm{ml} / \mathrm{dk}$ 'dan daha büyük olan hastalarda ve Child-Pugh sınıfı B veya daha düşük olan hepatik yetmezlik hastalarında doz ayarlaması gerekli değildir. Mikafungin kaspofungin ile karşılaştırıldığında daha az ilaç etkileşimi gösterir. Mikafunginin, siklosporin metabolizmasının inhibitörü olduğu ve birlikte kullanıldığında siklosporin düzeylerinin izlenmesi gerektiği yapılan bir çalışmada gösterilmiştir (118). Mikafungin iyi tolere edilir. Başlıca yan etkileri bulantı, kusma, baş ağrısı, diyare, flebit ve lökopenidir (56). Transaminaz ve alkalin fosfataz düzeylerinde yükselme görülebilir (107). Kızarıklık, kaşıntı, yüz şişmesi ve vazodilatasyon gibi histamin aracılı olası semptomlar, anaflaksi ve hemoliz de bu ilacın kullanımına eşlik edebilir (56).

\subsection{Anidulafungin}

Anidulafungin, ilk keşfedilen ve FDA onayı almış son ekinokandindir. 2006 yılında Candida spp. nin etkeni olduğu özofageal kandidiyaz, kandidemi, peritonit ve intra-abdominal apselerin tedavisinde kullanılmak üzere onaylandı (56). Kaspofungin ve mikafungin ile metabolik yolak, etki mekanizması ve antifungal spektrumu ortak özellikler göstermektedir (119). Anidulafungin, Aspergillus spp. (121), azol grubu antifungallere dirençli C. krusei, amfoterisin B'ye dirençli $C$. lusitaniae veya diğer ekinokandinlere dirençli C. parapsilosis $(120,121)$ dahil olmak üzere geniş 
bir Candida spp. grubuna karş1 in vitro ortamda son derece aktiftir. Ayrıca Aspergillus fumigatus ve diğer Aspergillus türlerine karşı önemli in vitro aktivite göstermiştir (122,123). Anidulafunginin Bipolaris spicifera, Exophiala jeanselmei, Fonsecaea pedrosoi, Madurella spp., Penicillium marneffei, Phialophora verrucosa, Pseudallescheria boydii ve Wanginella dermatitidis gibi küflere karşı in vitro aktiviteye sahip olduğu da gösterilmiştir (124). Cryptococcus ve Zigomisetlere karşı aktivitesi ise zayıftır $(95,125)$. Yapılan bir denemede özofageal kandidiyaz tedavisinde anidulafunginin flukonazol kadar etkili ve güvenli olduğu gösterilmiştir (126). Yapılan bir Faz II klinik çalışmasında da anidulafungin, invazif kandidiyazı tedavi etmiştir (127). Yaygın kandidiyazlı nötropenik bir tavşan modelinde anidulafunginin etkinliği değerlendirilmiş, $C$. albicans'1n böbreklerden doza bağlı bir şekilde temizlendiği ve hayatta kalma süresinin anlamlı derecede uzadığı gösterilmiştir (128). Yaygın aspergillosis hastalı̆̆ 1 olan bir tavşan modelinde anidulafunginin hayatta kalma süresini uzattığı saptanmıştır. Tedavi A. fumigatus üzerinde etkili olmuştur. İnvazif pulmoner aspergillosisli nötropenik tavşanlarda anidulafunginin etkinliğini değerlendiren bir çalışmada toksisite bulgusu olmaksızın hayatta kalma süresi uzamış ve pulmoner hasar azalmıştır (129).

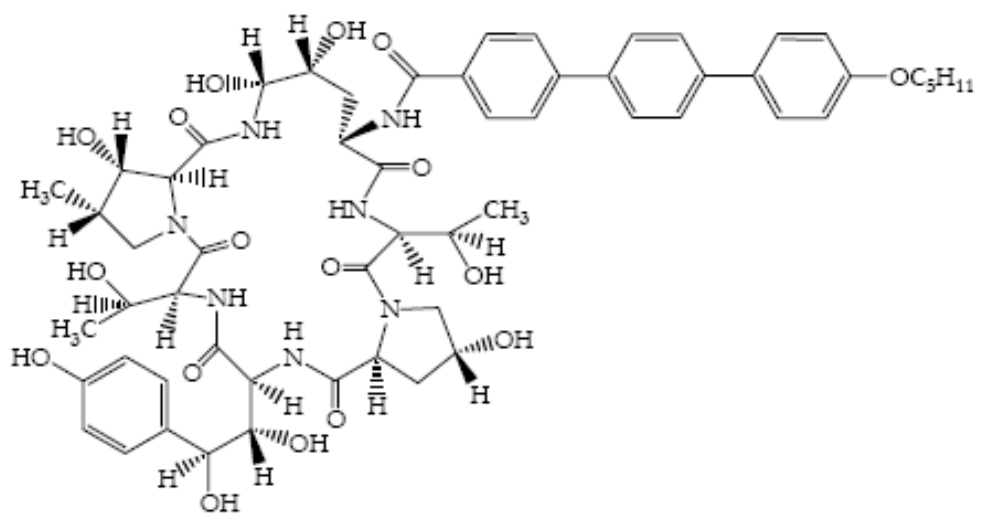

Şekil 6. Anidulafunginin kimyasal yapısı

Özofagial kandiyazis tedavisinde ilk gün bir defada $100 \mathrm{mg}$ anidulafungin yükleme dozu verilir. Bu dozu takiben uygulanan günlük bakım dozu 50 mg'dır (119).

Non-klinik çalışmalara göre anidulafungin yaklaşık \%84 oranında proteinlere bağlanır (130). Ayrıca anidulafungin, insan plazmasında yavaş bir şekilde parçalanma özelliği gösteren tek ilaçtır. Metabolizmadan çok bir biyotransformasyon işlemine uğrar. Bozunma ürünlerinin çoğu safra yolu ile feçese geçer. Ancak bu ürünler, çok küçük miktarlarda idrarda da belirlenmiştir. Değişmeden kalan ilaç miktarı ise feçeste \%10, idrarda ise \%1'den daha azdır. Anidulafungin yaklaşı 25 saatlik bir yarı ömüre sahiptir; oysa inaktif bozunma ürünlerinin yarı ömürleri yaklaşık 
4 gündür (131). Böbrek veya karaciğer yetmezliği olan hastalarda dozaj ayarlamasına gerek yoktur (119). Anidulafungin, sitokrom P450 sistemi ile etkileşmediği için siklosporin, vorikonazol, takrolimus, amfoterisin B veya rifampin ile önemli ilaç etkileşimleri göstermez. Burada siklosporin ile anidulafunginin etkileşme göstermemesi dikkate değer bir noktadır ve diğer ekinokandin türevi ilaçlarda bu durum görülmez (132).

Anidulafungin genellikle iyi tolere edilen bir ilaçtır. En sık karşılaşılan yan etkiler, hipotansiyon, kusma, kabızlık, bulantı, ateş, hipokalemi ve hepatik enzim düzeylerinde artıştır (132).

\section{SONUC}

Yeni geliştirilmiş geniş spektrumlu triazollerin ve ekinokandin türevi ilaçların antifungal tedaviye girmesi, fungal enfeksiyonların tedavisinde görevli sağlık çalışanlarına, geleneksel antifungal ilaçlara göre daha etkili ve daha az toksik alternatifler sunmuştur. Ayrıca farklı fungal yapıları hedefleyen antifungal kombinasyon kullanma olanağı da yaratmıştır. Kombine tedavi konusunda az sayıda klinik veri olmasına rağmen, antifungal ilaç kombinasyonu, özellikle, tedaviye dirençli mantar enfeksiyonları söz konusu olduğunda mantıklı bir seçenek olarak görülmektedir. Yeni geliştirilen 3 yeni ekinokandin türevi ilaç, kaspofungin, mikafungin ve anidulafungin, aktivite spektrumu, farmakokinetik ve antifungal etkinlik bakımından birbirine benzer özellikler taşımaktadır. Bu ilaçların, özellikle kandidemi ve invazif kandidiyaz tedavisi için standart tedavi olmaları beklenmektedir. Yeni triazol türevi antifungal ilaçlar ise Candida türleri, filamentöz mantarlar ve dimorfik endemik mikozlar dahil çok geniş bir antifungal aktivite spektrumuna sahiptir. Vorikonazol, invazif aspergillosis için seçimli ilaç niteliğini kazanmış ve küf enfeksiyonlarında yararlılığını kanıtlamıştır. Posakonazolün, özellikle Zigomikozis tedavisinde amfoterisin B ile kombine halde kullanımının artması beklenen bir gelişmedir.

Antifungal tedavi konusunda kaydedilen bu ilerlemelere rağmen, invazif mantar enfeksiyonlarından kaynaklanan mortalite oranları belli hasta gruplarında halen yüksektir. Antifungal tedavi alanında yeni seçeneklerin sunulabilmesi için mantarlara karşı son derece etkili, farklı fungal yapıları hedefleyen farklı etki mekanizmalarına sahip, hem oral hem de parenteral yolla alınabilen formülasyonları olan, son derece güvenli ve mümkün olabildiğince ekonomik ilaçlara gereksinim vardır. Dolayısıyla, sözü edilen bu özellikleri taşıyan antifungal ilaçların geliştirilmesi güncelliği olan bir konudur ve önümüzdeki y1llarda bu hedefler doğrultusunda yoğun bir çaba sarfedilmesi kaçınılmaz görünmektedir. 


\section{KAYNAKLAR}

1. Ellis, M., "Invasive fungal infections; evolving challenges for diagnosis and therapeutics" Mol. Immunol, 38, 947-957, (2002).

2. Edmond, M.B., Wallace, S.E., McClish, D.K., Pfaller, M.A., Jones, R.N., Wenzel, R.P., "Nosocomial bloodstream infections in United States hospitals: a three-year analysis" Clin. Infect. Dis, 29, 239-244, (1999).

3. Denning, D.W., "Invasive aspergillosis" Clin. Infect. Dis, 26, 781-805, (1998).

4. Paterson, D.L., Singh, N., "Invasive aspergillosis in transplant recipients" Medicine, 78, 123-138, (1999).

5. Rex, J.H., Walsh, T.J., Sobel, J.D., Filler, S.G., Pappas, P.G., Dismukes, W.E., Edwards, J.E., "Practise guidelines for the treatment of candidiasis" Clin. Infect. Dis, 30, 662-678, (2000).

6. Denning, D.W., "Therapeutic outcome in invasive aspergillosis" Clin. Infect. Dis, 23, 608615, (1996).

7. Lin, S.J., Schranz, J., Teutsch, S.M., “Aspergillosis case-fatality rate: systematic review of the literature" Clin. Infect. Dis, 32, 358-366, (2001).

8. Wingard, J.R., Leather, H., "A new era of antifungal therapy" Biol. Blood Marrow Transplant, 10, 73-90, (2004).

9. Blumberg, H.M., Jarvis, W.R., Soucie, J.M., Edwards, J.E., Patterson, J.E., Pfaller, M.A., Rangel-Frausto, M.S., Rinaldi, M.G., Saiman, L., Wiblin, R.T., Wenzel, R.P., "Risk factors for candidal bloodstream infections in surgical intensive care unit patients: The NEMIS prospective multicenter study. The National Epidemiology of Mycosis Survey" Clin. Infect. Dis, 33, 177-186, (2001).

10. McNeil, M.M., Nash, S.L., Hajjeh, R.A., Phelan, M.A., Conn, L.A., Plikaytis, B.D., Warnock, D.W., "Trends in mortality due to invasive mycotic diseases in the United States, 1980-1997" Clin. Infect. Dis, 33, 641-647, (2001).

11. Viscoli, C., Girmenia, C., Marinus, A., Collette, L., Martino, P., Vandercam, B., Doyen, C., Lebeau, B., Spence, D., Kremery, V., de Pauw, B., Meunier, F., "Candidemia in cancer patients: a prospective, multicenter surveillance study by the Invasive Fungal Infection Group (IFIG) of the European Organization for Research and Treatment of Cancer (EORTC)" Clin. Infect. Dis, 28, 1071-1079, (1999). 
12. Rangel-Frausto, M.S., Wiblin, T., Blumberg, H.M., Saiman, L., Patterson, J., Rinaldi, M., Pfaller, M., Edwards Jr, J.E., Jarvis, W., Dawson, J., Wenzel, R.P., "National Epidemiology of Mycoses Survey (NEMIS): variations in rates of bloodstream infections due to Candida species in seven surgical intensive care units and six neonatal intensive care units" Clin. Infect. Dis, 29, 253-258, (1999).

13. Blignaut, E., Messer, S., Hollis, R.J., Pfaller, M.A., "Antifungal susceptibility of South African oral yeast isolates from HIV/AIDS patients and healthy individuals" Diagn. Microbiol. Infect. Dis, 44, 169-174, (2002).

14. Vazquez, J.A., "Therapeutic options fort he management of oropharyngeal and esophageal candidiasis in HIV/AIDS patients" HIV Clin. Trials, 1, 47-59, (2000).

15. Samaranayake, L.P., "Oral mycoses in HIV infection" Oral Surg. Oral Med. Oral Pathol, 73, 171-180, (1992).

16. Ribaud, P., Chastang, C., Latgé, J.P., Baffroy-Lafitte, L., Parquet, N., Devergie, A., Espérou, H., Sélimi, F., Rocha, V., Derouin, F., Socié, G., Gluckman, E., "Survival and prognostic factors of invasive aspergillosis after allogeneic bone marrow transplantation" Clin. Infect. Dis, 28, 328-330, (1999).

17. Moore, R.D., Chaisson, R.E., "Natural history of opportunistic disease in an HIV-infected urban clinical cohort" Ann. Intern. Med, 124, 633-642, (1996).

18. Supparatpinyo, K., Khamwan, C., Baosoung, V., Nelson, K.E., Sirisanthana, T., "Disseminated Penicillium marneffei infection in southeast Asia" Lancet, 344, 110-113, (1994).

19. Rodriguez, C.A., Patrick, C.C., "Current approach to invasive aspergillosis" Pediatr. Infect. Dis, 20, 312-314, (2001).

20. Kontoyiannis, D.P., "A clinical perspective for the management of invasive fungal infections: focus on IDSA guidelines. Infectious Diseases Society of America" Pharmacotherapy, 21, 175S-187S, (2001).

21. Ostrosky-Zeichner, L., Marr, K.A., Rex, J.H., Cohen, S.H., "Amphotericin B: time for a new 'gold standard"' Clin. Infect. Dis, 37, 415-425, (2003).

22. Chandrasekar, P.H., Cutright, J.L., Manavathu, E.K., "Aspergillus: rising frequency of clinical isolation and continued susceptibility to antifungal agents 1994-1999" Diagn. Microbial. Infect. Dis, 41, 211-214, (2001). 
23. Patterson, T.F., "Current and future approaches to antifungal therapy" Curr. Opin. Infect. Dis, 13, 579-581, (2000).

24. Ernst, E.J., "Investigational antifungal agents" Pharmacotherapy, 21, 165S-174S, (2001).

25. Odds, F.C., "Antifungal agents: their diversity and increasing sophistication" Mycologist, 17, 51-55, (2003).

26. Girmenia, C., Luzi, G., Monaco, M., Martino, P., "Use of voriconazole in treatment of Scedosporium apiospermum infection: case report" J. Clin. Microbiol, 36, 1436-1438, (1998).

27. Podust, L.M., Poulos, T.L., Waterman, M.R., "Crystal structure of cytochrome P450 14 sterol demethylase (CYP51) from Mycobacterium tuberculosis in complex with azole inhibitors" Proc. Natl. Acad. Sci. USA, 98, 3068-3073, (2001).

28. Xiao, L., Madison, V., Chau, A.S., Loebenberg, D., Palermo, R.E., McNicholas, P.M., "Three-dimensional models of wild-type and mutated forms of cytochrome P450 14 -sterol demethylases from Aspergillus fumigatus and Candida albicans provide insights into posaconazole binding" Antimicrob. Agents Chemother, 48, 568-574, (2004).

29. Sanati, H., Belanger, P., Fratti, R., Ghannoum, M., "A new triazole, voriconazole (UK109,496), blocks sterol biosynthesis in Candida albicans and Candida krusei" Antimicrob. Agents Chemother, 41, 2492-2496, (1997).

30. Herbrecht, R., "Voriconazole: therapeutic review of a new azole antifungal" Expert Rev. Anti. Infect. Ther, 2, 485-497, (2004).

31. Espinel-Ingroff, A., Boyle, K., Sheehan, D.J., "In vitro antifungal activities of voriconazole and reference agents as determined by NCCLS methods: review of the literature" Mycopathologia, 150, 101-115, (2001).

32. Tattevin, P., Bruneel, F., Lellouche, F., de Broucker, T., Chevret, S., Wolff, M., Regnier, B., "Successful treatment of brain aspergillosis with voriconazole" Clin. Microbiol. Infect, 10, 928-931, (2004).

33. Schwartz, S., Milatovic, D., Thiel, E., "Succesful treatment of cerebral aspergillosis with a novel triazole (voriconazole) in a patient with acute leukaemia" Br. J. Haematol, 97, 663-665, (1997).

34. Nesky, M.A., McDougal, E.C., Peacock Jr, J.E., "Pseudallescheria boydii brain abscess successfully treated with voriconazole and surgical drainage: case report and literature review of central nervous system pseudallescheriasis" Clin. Infect. Dis, 31, 673-677, (2000). 
35. Poza, G., Montoya, J., Redondo, C., Ruiz, J., Vila, N., Rodriguez-Tudela, J.L., Ceron, A., Simarro, E., "Meningitis caused by Pseudallescheria boydii treated by voriconazole" Clin. Infect. Dis, 30, 981-982, (2000).

36. Bakleh, M., Aksamit, A.J., Tleyjeh, I.M., Marshall, W.F., "Successful treatment of cerebral blastomycosis with voriconazole" Clin. Infect. Dis, 40, e69-71, (2005).

37. Mouas, H., Lutsar, I., Dupont, B., Fain, O., Herbrecht, R., Lescure, F.X., Lortholary, O., "Voriconazole for invasive bone aspergillosis: a worldwide experience of 20 cases" Clin. Infect. Dis, 40, 1141-1147, (2005).

38. Studahl, M., Backteman, T., Stalhammar, F., Cryssanthou, E., Petrini, B., "Bone and joint infection after traumatic implantation of Scedosporium prolificans with voriconazole and surgery" Acta. Paediatr, 92, 980-982, (2003).

39. Breit, S.M., Hariprasad, S.M., Mieler, W.F., Shah, G.K., Mills, M.D., Grand, M.G., "Management of endogenous fungal endophtalmitis with voriconazole and caspofungin" Am. J. Ophthalmol, 139, 135-140, (2005).

40. Herbrecht, R., Denning, D.W., Patterson, T.F., Bennett, J.E., Greene, R.E., Oestmann, J.W., Kern, W.V., Marr, K.A., Ribaud, P., Lortholary, O., Sylvester, R., Rubin, R.H., Wingard, J.R., Stark, P., Durand, C., Caillot, D., Thiel, E., Chandrasekar, P.H., Hodges, M.R., Schlamm, H.T., Troke, P.F., de Pauw, B., "Voriconazole versus amphotericin B for primary therapy of invasive aspergillosis" N. Engl. J. Med, 347, 408-415, (2002).

41. Denning, D.W., Ribaud, P., Milpied, N., Caillot, D., Herbrecht, R., Thiel, E., Haas, A., Ruhnke, M., Lode, H., "The efficacy and safety of voriconazole in the treatment of acute invasive aspergillosis" Clin. Infect. Dis, 34, 563-571, (2002).

42. Steinbach, W.J., Benjamin Jr, D.K., Kontoyiannis, D.P., Perfect, J.R., Lutsar, I., Marr, K.A., Lionakis, M.S., Torres, H.A., Jafri, H., Walsh, T.J., "Infections due to Aspergillus terreus: a multicenter retrospective analysis of 83 cases" Clin. Infect. Dis, 39, 192-198, (2004).

43. Walsh, T.J., Pappas, P., Winston, D.J., Lazarus, H.M., Petersen, F., Raffalli, J., Yanovich, S., Stiff, P., Greenberg, R., Donowitz, G., Schuster, M., Reboli, A., Wingard, J., Arndt, C., Reinhardt, J., Hadley, S., Finberg, R., Laverdiére, M., Perfect, J., Garber, G., Fioritoni, G., Anaissie, E., Lee, J., "Voriconazole compared with liposomal amphotericin 
B for empirical antifungal therapy in patients with neutropenia and persistent fever" N. Engl. J. Med, 346, 225-234, (2002).

44. Hoffman, H.L., Rathbun, R.C., "Review of the safety and efficacy of voriconazole" Expert Opin. Investig. Drugs, 11, 409-429, (2002).

45. Imhof, A., Balajee, S.A., Fredricks, D.N., Englund, J.A., Marr, K.A., "Breakthrough fungal infections in stem cell transplant recipients receiving voriconazole" Clin. Infect. Dis, 39, 743-746, (2004).

46. Levêque, D., Nivoix, Y., Jehl, F., Herbrecht, R., "Clinical Pharmacokinetics of Voriconazole: review" Int. J. Of Antimicrob. Agents, 27, 274-284, (2006).

47. Trifilio, S., Ortiz, R., Pennick, G., Verma, A., Pi, J., Stosor, V., Zembower, T., Mehta, J., "Voriconazole therapeutic drug monitoring in allogeneic hematopoietic stem cell transplant recipients" Bone Marrow Transplant, 35, 509-513, (2005).

48. Theuretzbacher, U., Ihle, F., Derendorf, H., "Pharmacokinetic/pharmacodynamic profile of voriconazole" Clin. Pharmacokinet, 45, 649-663, (2006).

49. Reis, A., Sundmacher, R., Tintelnot, K., Agostini, H., Jensen, H.E., Althaus, C., "Successful treatment of ocular invasive mould infection (fusariosis) with the new antifungal agent voriconazole" Br. J. Ophtalmol, 84, 932-933, (2000).

50. Klont, R.R., Eggink, C.A., Rijs, A.J., Wesseling, P., Verweij, P.E., "Successful treatment of Fusarium keratitis with cornea transplantation and topical and systemic voriconazole" Clin. Infect. Dis, 40, e110-112, (2005).

51. Roffey, S.J., Cole, S., Comby, P., Gibson, D., Jezequel, S.G., Nedderman, A.N., Smith, D.A., Walker, D.K., Wood, N., "The disposition of voriconazole in mouse, rat, rabbit, guinea pig, dog, and human" Drug Metab. Dispos, 31, 731-741, (2003).

52. Hyland, R., Jones, B.C., Smith, D.A., "Identification of the cytochrome P450 enzymes involved in the N-oxidation of voriconazole" Drug Metab. Dispos, 31, 540-547, (2003).

53. Pearson, M.M., Rogers, P.D., Cleary, J.D., Chapman, S.W., "Voriconazole: a new triazole antifungal agent" Ann. Pharmacother, 37, 420-432, (2003).

54. Peng, L.W., Lien, Y.H., "Pharmacokinetics of single, oral-dose voriconazole in peritoneal dialysis patients" Am. J. Kidney Dis, 45, 162-166, (2005). 
55. Venkatakrishnan, K., von Moltke, L.L., Greenblatt, D.J., "Effects of antifungal agents on oxidative drug metabolism: clinical relevance" Clin. Pharmacokinet, 38, 111-180, (2000).

56. Petrikkos, G., Skiada, A., "Recent advances in antifungal chemotherapy: review" Int. J. Antimicrob. Agents, 30, 108-117, (2007).

57. Walsh, T.J., Viviani, M.A., Arathoon, E., Chiou, C. Ghannoum, M. Groll, A.H., Odds, F.C., "New targets and delivery systems for antifungal therapy" Med. Mycol, 38 (suppl 1), $335-347,(2000)$.

58. Law, D., Moore, C.B., Denning, D.W., "Activity of SCH 56592 compared with those of fluconazole and itraconazole against Candida spp." Antimicrob. Agents Chemother, 41, 23102311, (1997).

59. Galgiani, J.N., Lewis, M.L., "In vitro studies of activities of the antifungal triazoles SCH 56592 and itraconazole against Candida albicans, Cryptococcus neoformans, and other pathogenic yeasts" Antimicrob. Agents Chemother, 41, 180-183, (1997).

60. Oakley, K.L., Moore, C.B., Denning, D.W., "In vitro activity of SCH-56592 and comparison with activities of amphotericin B and itraconazole against Aspergillus spp." Antimicrob. Agents Chemother, 41, 1124-1126, (1997).

61. Marco, F., Pfaller, M.A., Messer, S.A., Jones, R.N., "In vitro activity of a new triazole antifungal agent, SCH 56592, against clinical isolates of filamentous fungi” Mycopathologia, 141, 73-77, (1998).

62. Gonzalez, G.M., Fothergill, A.W., Sutton, D.A., Rinaldi, M.G., Loebenberg, D., "In vitro activities of new and established triazoles against opportunistic filamentous and dimorphic fungi" Med. Mycol, 43, 281-284, (2005).

63. Espinel-Ingroff, A., "In vitro antifungal activities of anidulafungin and micafungin, licensed agents and the investigational triazole posaconazole as determined by NCCLS methods for 12,052 fungal isolates: review of the literature" Rev. Iberoam. Micol, 20, 121-136, (2003).

64. Paphitou, N.I., Ostrosky-Zeichner, L., Paetznick, V.L., Rodriguez, J.R., Chen, E., Rex, J. H., "In vitro antifungal susceptibilities of Trichosporon species" Antimicrob. Agents Chemother, 46, 1144-1146, (2002).

65. Graybill, J.R., Hernandez, S., Bocanegra, R., Najvar, L.K., "Antifungal therapy of murine Aspergillus terreus infection" Antimicrob. Agents Chemother, 48, 3715-3719, (2004). 
66. Walsh, T.J., Petraitis, V., Petraitiene, R., Field-Ridley, A., Sutton, D., Ghannoum, M., Sein, T., Schaufele, R., Peter, J., Bacher, J., Casler, H., Armstrong, D., Espinel-Ingroff, A., Rinaldi, M.G., Lyman, C.A., "Experimental pulmonary aspergillosis due to Aspergillosis terreus: pathogenesis and treatment of an emerging fungal pathogen resistant to amphotericin B” J. Infect. Dis, 188, 305-319, (2003).

67. Paphitou, N.I., Ostrosky-Zeichner, L., Paetznick, V.L., Rodriguez, J.R., Chen, E., Rex, J.H., "In vitro activities of investigational triazoles against Fusarium species: effects of inoculum size and incubation time on broth microdilution susceptibility test results" Antimicrob. Agents Chemother, 46, 3298-3300, (2002).

68. Sun, Q.N., Fothergill, A.W., McCarthy, D.I., Rinaldi, M.G., Graybill, J.R., "In vitro activities of posaconazole, itraconazole, voriconazole, amphotericin $\mathrm{B}$, and fluconazole against 37 clinical isolates of zygomycetes" Antimicrob. Agents Chemother, 46, 1581-1582, (2002).

69. Nucci, M., Akiti, T., Barreiros, G., Silveira, F., Revankar, S.G., Sutton, D.A., Patterson, T.F., "Nosocomial fungemia due to Exophiala jeanselmei var. jeanselmei and a Rhinocladiella species: newly described causes of bloodstream infection" J. Clin. Microbiol, 39, 514-518, (2001).

70. Vazquez, J.A., Skiest, D.J., Nieto, L., Northland, R., Sanne, I., Gogate, J., Greaves, W., Isaacs, R., "A multicenter randomized trial evaluating posaconazole versus fluconazole for the treatment of oropharyngeal candidiasis in subjects with HIV/AIDS" Clin. Infect. Dis, $\mathbf{4 2}$, 1179-1186, (2006).

71. Cornely, O.A., Maertens, J., Winston, D.J., Perfect, J., Ullmann, A.J., Walsh, T.J., Helfgott, D., Holowiecki, J., Stockelberg, D., Goh, Y.T., Petrini, M., Hardalo, C., Suresh, R., Angulo-Gonzalez, D., "Posaconazole vs. fluconazole or itraconazole prophylaxis in patients with neutropenia" N. Engl. J. Med, 356, 348-359, (2007).

72. Ullmann, A.J., Lipton, J.H., Vesole, D.H., Chandrasekar, P., Langston, A., Tarantolo, S.R., Greinix, H., Morais de Azevedo, W., Reddy, V., Boparai, N., Pedicone, L., Patino, H., Durrant, S., "Posaconazole or fluconazole for prophylaxis in severe graft-versus-host disease" N. Engl. J. Med, 356, 335-347, (2007).

73. Raad, I.I., Hachem, R.Y., Herbrecht, R., Graybill, J.R., Hare, R., Corcoran, G., Kontoyiannis, D.P., "Posaconazole as salvage treatment for invasive fusariosis in patients 
with underlying hematologic malignancy and other conditions" Clin. Infect. Dis, 42, 13981403, (2006).

74. Pitisuttithum, P., Negroni, R., Graybill, J.R., Bustamante, B., Pappas, P., Chapman, S., Hare, R.S., Hardalo, C.J., "Activity of posaconazole in the treatment of central nervous system fungal infections" J. Antimicrob. Chemother, 56, 745-755, (2005).

75. Anstead, G.M., Corcoran, G., Lewis, J., Berg, D., Graybill, J.R., "Refractory coccidioidomycosis treated with posaconazole" Clin. Infect. Dis, 40, 1770-1776, (2005).

76. Ezzet, F., Wexler, D., Courtney, R., Krishna, G., Lim, J., Laughlin, M., "Oral bioavailabilitiy of posaconazole in fasted healthy subjects: comparison between three regimens and basis for clinical dosage recommendations" Clin. Pharmacokinet, 44, 211-220, (2005).

77. Kauffman, C.A., "Clinical efficacy of new antifungal agents" Curr. Opin. Microbiol, 9, 483-488, (2006).

78. Courtney, R., Radwanski, E., Lim, J., Laughlin, M., "Pharmacokinetics of posaconazole coadministered with antacid in fasting or nonfasting healthy men" Antimicrob. Agents Chemother, 48, 804-808, (2004).

79. Courtney, R., Pai, S., Laughlin, M., Lim, J., Batra, V., "Pharmacokinetics, safety, and tolerability of oral posaconazole administered in single and multiple doses in healthy adults" Antimicrob. Agents Chemother, 47, 2788-2795, (2003).

80. Herbrecht, R., "Posaconazole: a potent, extended-spectrum triazole anti-fungal for the treatment of serious fungal infections" Int. J. Clin. Pract, 58, 612-624, (2004).

81. Krieter, P., Flannery, B., Musick, T., Gohdes, M., Martinho, M., Courtney, R., "Disposition of posaconazole following single-dose oral administration in healthy subjects" Antimicrob. Agents Chemother, 48, 3543-3551, (2004).

82. Courtney, R., Sansone, A., Smith, W., Marbury, T., Statkevich, P., Martinho, M., Laughlin, M., Swan, S., "Posaconazole pharmacokinetics, safety, and tolerability in subjects with varying degrees of chronic renal disease" J. Clin. Pharmacol, 45, 185-192, (2005).

83. Perfect, J.R., Cox, G.M., Dodge, R.K., Schell, W.A., "In vitro and in vivo efficacies of the azole SCH56592 against Cryptococcus neoformans" Antimicrob. Agents Chemother, 40, 1910-1913, (1996). 
84. Al-Abdely, H.M., Alkhunaizi, A.M., Al-Tawfiq, J.A., Hassounah, M., Rinaldi, M.G., Sutton, D.A., "Successful therapy of cerebral phaeohyphomycosis due to Ramichloridium mackenziei with the new triazole posaconazole" Med. Mycol, 43, 91-95, (2005).

85. Groll, A.H., Walsh, T.J., "Posaconazole: clinical pharmacology and potential for management of fungal infections" Expert Rev. Anti. Infect. Ther, 3, 467-487, (2005).

86. Herbrecht, R., Nivoix, Y., Fohrer, C., Natarajan-Ame, S., Letscher-Bru, V., "Management of systemic fungal infections: alternatives to itraconazole" J. Antimicrob. Chemother, 56 (supp 1), i39-i48, (2005).

87. Raad, I.I., Graybill, J.R., Bustamante, A.B., Cornely, O.A., Gaona-Flores, V., Afif, C., Graham, D.R., Greenberg, R.N., Hadley, S., Langston, A., Negroni, R., Perfect, J.R., Pitisuttithum, P., Restrepo, A., Schiller, G., Pedicone, L., Ullmann, A.J., "Safety of longterm oral posaconazole use in the treatment of refractory invasive fungal infections" Clin. Infect. Dis, 42, 1726-1734, (2006).

88. Wexler, D., Courtney, R., Richards, W., Banfield, C., Lim, J., Laughlin, M., "Effect of posaconazole on cytochrome P450 enzymes: a randomized, open-label, two-way crossover study" Eur. J. Pharm. Sci, 21, 645-653, (2004).

89. Segal, B.H., Barnhart, L.A., Anderson, V.L., Walsh, T.J., Malech, H.L., Holland, S.M., "Posaconazole as salvage therapy in patients with chronic granulomatous disease and invasive filamentous fungal infection" Clin. Infect. Dis, 40, 1684-1688, (2005).

90. Yamazumi, T., Pfaller, M.A., Messer, S.A., Houston, A., Hollis, R.J., Jones, R.N., "In vitro activities of ravuconazole (BMS-207147) against 541 clinical isolates of Cryptococcus neoformans" Antimicrob. Agents Chemother, 44, 2883-2886, (2000).

91. Pfaller, M.A., Messer, S.A., Hollis, R.J., Jones, R.N., Diekema, D.J., "In vitro activities of ravuconazole and voriconazole compared with those of four approved systemic antifungal agents against 6,970 clinical isolates of Candida spp." Antimicrob. Agents Chemother, 46, 1723-1727, (2002).

92. Cuenca-Estrella, M., Gomez-Lopez, A., Mellado, E., Garcia-Effron, G., Monzon, A., Rodriguez-Tudela, J.L., "In vitro activity of ravuconazole against 923 clinical isolates of nondermatophyte filamentous fungi" Antimicrob. Agents Chemother, 49, 5136-5138, (2005).

93. Neely, M.N., Ghannoum, M.A., "The exciting future of antifungal therapy" Eur. J. Clin. Microbiol. Infect. Dis, 19, 897-914, (2000). 
94. Onishi, J., Meinz, M., Thompson, J., Curotto, J., Dreikorn, S., Rosenbach, M., Douglas, C., Abruzzo, G., Flattery, A., Kong, L., Cabello, A., Vicente, F., Pelaez, F., Diez, M.T., Martin, I., Bills, G., Giacobbe, R., Dombrowski, A., Schwartz, R., Morris, S., Harris, G., Tsipouras, A., Wilson, K., Kurtz, M.B., "Discovery of novel antifungal (1,3)- -d-glucan synthase inhibitors" Antimicrob. Agents Chemother, 44, 368-377, (2000).

95. Denning, D.W., "Echinocandin antifungal drugs" Lancet, 362, 1142-1151, (2003).

96. Moudgal, V., Little, T., Boikov, D., Vazquez, J.A., "Multiechinocandin- and multiazoleresistant Candida parapsilosis isolates serially obtained during therapy for prosthetic valve endocarditis" Antimicrob. Agents Chemother, 49, 767-769, (2005).

97. Hernandez, S., Lopez-Ribot, J.L., Najvar, L.K., McCarthy, D.I., Bocanegra, R., Graybill, J.R., "Caspofungin resistance in Candida albicans: correlating clinical outcome with laboratory susceptibility testing of three isogenic isolates serially obtained from a patient with progressive Candida esophagitis" Antimicrob. Agents Chemother, 48, 1382-1383, (2004).

98. Krogh-Madsen, M., Arendrup, M.C., Heslet, L., Knudsen, J.D., "Amphotericin B and caspofungin resistance in Candida glabrata isolates recovered from a critically ill patient" Clin. Infect. Dis, 42, 938-944, (2006).

99. Pfaller, M.A., Marco, F., Messer, S.A., Jones, R.N., "In vitro activity of two echinocandin derivatives, LY303366 and MK-0991 (L-743,792), against clinical isolates of Aspergillus, Fusarium, Rhizopus and other filamentous fungi” Diagn. Microbiol. Infect. Dis, 30, 251-255, (1998).

100. Abruzzo, G.K., Flattery, A.M., Gill, C.J., Kong, L., Smith, J.G., Pikounis, V.B., Balkovec, J.M., Bouffard, A.F., Dropinski, J.F., Rosen, H., Kropp, H., Bartizal, K., "Evaluation of echinocandin antifungal MK-0991 (L-743,872): efficacies in mouse models of disseminated aspergillosis, candidiasis and cryptococcosis" Antimicrob. Agents Chemother, 41, 2333-2338, (1997).

101. Mora-Duarte, J., Betts, R., Rotstein, C., Colombo, A.L., Thompson-Moya, L., Smietana, J., Lupinacci, R., Sable, C., Kartsonis, N., Perfect, J., "Comparison of caspofungin and amphotericin B for invasive candidiasis" N. Engl. J. Med, 347, 2020-2029, (2002).

102. Walsh, T., Teppler, H., Donowitz, G.R., Maertens, J.A., Baden, L.R., Dmoszynska, A., Cornely, O.A., Bourque, M.R., Lupinacci, R.J., Sable, C.A., de Pauw, B.E., "Caspofungin 
versus liposomal amphotericin B for empirical antifungal therapy in patients with persistent fever and neutropenia" N. Engl. J. Med, 351, 1391-1402, (2004).

103. Villanueva, A., Arathoon, E.G., Gotuzzo, E., Berman, R.S., DiNubile, M.J., Sable, C.A., "A randomized double-blind study of caspofungin versus amphotericin for the treatment of candidal esophagitis" Clin. Infect. Dis, 33, 1529-1535, (2001).

104. Arathoon, E.G., Gotuzzo, E., Noriega, L.M., Berman, R.S., DiNubile, M.J., Sable, C.A., "Randomized, double-blind, multicenter study of caspofungin versus amphotericin B for treatment of oropharyngeal and esophageal candidiases" Antimicrob. Agents Chemother, 46, 451-457, (2002).

105. Hebert, M.F., Blough, D.K., Townsend, R.W., Allison, M., Buell, D., Keirns, J., Bekersky, I., "Concomitant tacrolimus and micafungin pharmacokinetics in healthy volunteers" J. Clin. Pharmacol, 45, 1018-1024, (2005).

106. https://utdol.com $(09 / 05 / 2008)$

107. Yang, A., Kerdel, F.A., "Infectious disease update: new anti-microbials" Semin. Cutan. Med. Surg, 25, 94-99, (2006).

108. Stone, J.A., Migoya, E.M., Hickey, L., Winchell, G.A., Deutsch, P.J., Ghosh, K., Freeman, A., Bi, S., Desai, R., Dilzer, S.C., Lasseter, K.C., Kraft, W.K., Greenberg, H., Waldman, S.A., "Potential for interactions between caspofungin and nelfinavir or rifampin" Antimicrob. Agents Chemother, 48, 4306-4314, (2004).

109. "Caspofungin (Cancidas) for aspergillosis" Med. Lett. Drugs Ther, 43, 58-59, (2001).

110. “Cancidas prescribing information" Merck\&Co. Whitehouse Station, NJ: Merck, (2004).

111. de Wet, N., Llanos-Cuentas, A., Suleiman, J., Baraldi, E., Krantz, E.F., Della Negra, M., Diekmann-Berndt, H., "A randomized, double-blind, parallel-group, dose-response study of micafungin compared with fluconazole for the treatment of esophageal candidiasis in HIVpositive patients" Clin. Infect. Dis, 39, 842-849, (2004).

112. Ostrosky-Zeichner, L., Kontoyiannis, D., Raffalli, J., Mullane, K.M., Vazquez, J., Anaissie, E.J., Lipton, J., Jacobs, P., van Rensburg, J.H., Rex, J.H., Lau, W., Facklam, D., Buell, D.N., "International, open-label, noncomparative, clinical trial of micafungin alone and in combination for treatment of newly diagnosed and refractory candidemia" Eur. J. Clin. Microbiol. Infect. Dis, 24, 654-661, (2005). 
113. Van Burik, J.A., Ratanatharathorn, V., Stepan, D.E., Miller, C.B., Lipton, J.H., Vesole, D.H., Bunin, N., Wall, D.A., Hiemenz, J.W., Satoi, Y., Lee, J.M., Walsh, T.J., "Micafungin versus fluconazole for prophylaxis against invasive fungal infections during neutropenia in patients undergoing hematopoietic stem cell transplantation" Clin. Infect. Dis, 39, 1407-1416, (2004).

114. Ota, S., Tanaka, J., Kahata, K., Toubai, T., Kondo, K., Mori, A., Toyoshima, N., Musashi, M., Asaka, M., Imamura, M., "Successful micafungin (FK463) treatment of invasive pulmonary aspergillosis in a patient with acute lymphoblastic leukemia in a phase II study" Int. J. Hematol, 79, 390-393, (2004).

115. Yokote, T., Akioka, T., Oka, S., Fujisaka, T., Yamano, T., Hara, S., Tsuji, M., Hanafusa, T., "Successful treatment with micafungin of invasive pulmonary aspergillosis in acute myeloid leukemia, with renal failure due to amphotericin B therapy" Ann. Hematol, 83, 64-66, (2004).

116. Singer, M.S., Seibel, N.L., Vezina, G., Choi, S.S., Dinndorf, P.A., "Successful treatment of invasive aspergillosis in two patients with acute myelogenous leukaemia" J. Pediatr. Hematol. Oncol, 25, 252-256, (2003).

117. Hebert, M.F., Smith, H.E., Marbury, T.C., Swan, S.K., Smith, W.B., Townsend, R.W., Buell, D., Keirns, J., Bekersky, I., "Pharmacokinetics of micafungin in healthy volunteers, volunteers with moderate liver disease, and volunteers with renal dysfunction" J. Clin. Pharmacol, 45, 1145-1152, (2005).

118. Hebert, M.F., Townsend, R.W., Austin, S., Balan, G., Blough, D.K., Buell, D., Keirns, J., Bekersky, I., "Concomitant cyclosporine and micafungin pharmacokinetics in healthy volunteers" J. Clin. Pharmacol, 45, 954-960, (2005).

119. http://www.pfizer.com/pfizer/download/uspi_eraxis.pdf $(04 / 05 / 2006)$

120. Arévalo, M.P., Carrillo-Muñoz, A.J., Salgado, J., Cardenes, D., Brio, S., Quindos, G., Espinel-Ingroff, A., "Antifungal activity of the echinocandin anidulafungin (VER002,LY303366) against yeast pathogens: a comparative study with M27-A microdilution method" $J$. Antimicrob. Chemother, 51, 163-166, (2003).

121. Zhanel, G.G., Karlowsky, J.A., Harding, G.A., Balko, T.V., Zelenitsky, S.A., Friesen, M., Kabani, A., Turik, M., Hoban, D.J., "In vitro activity of a new semisynthetic echinocandin, LY-303366, against systemic isolates of Candida species, Cryptococcus 
neoformans, Blastomyces dermatitidis, and Aspergillus species" Antimicrob. Agents Chemother, 41, 863-865, (1997).

122. Serrano Mdel, C., Valverde-Conde, A., Chavez, M.M., Bernal, S., Claro, R.M., Peman, J., Ramirez, M., Martin-Mazuelos, E., "In vitro activity of voriconazole, itraconazole, caspofungin, anidulafungin (VER002,LY-303366) and amphotericin B against Aspergillus spp.” Diagn. Microbiol. Infect. Dis, 45, 131-135, (2003).

123. Petraitis, V., Petraitiene, R., Groll, A.H., Bell, A., Callender, D.P., Sein, T., Schaufele, R.L., McMillian, C.L., Bacher, J., Walsh, T.J., "Antifungal efficacy, safety, and single-dose pharmacokinetics of LY303366, a novel echinocandin B, in experimental pulmonary aspergillosis in persistently neutropenic rabbits" Antimicrob. Agents Chemother, 42, 28982905, (1998).

124. Odabasi, Z., Paetznick, V.L., Rodriguez, J.R., Chen, E., Ostrosky-Zeichner, L., "In vitro activity anidulafungin against selected clinically important mold isolates" Antimicrob. Agents Chemother, 48, 1912-1915, (2004).

125. Ernst, E.J., Klepser, M.E., Pfaller, M.A., "Postantifungal effects of echinocandin, azole, and polyene antifungal agents against Candida albicans and Cryptococcus neoformans" Antimicrob. Agents Chemother, 44, 1108-1111, (2000).

126. Krause, D.S., Simjee, A.E., van Rensburg, C., Viljoen, J., Walsh, T.J., Goldstein, B.P., Wible, M., Henkel, T., "A randomized, double-blind trial of anidulafungin versus fluconazole for the treatment of esophageal candidiasis" Clin. Infect. Dis, 39, 770-775, (2004).

127. Pfaller, M.A., Diekema, D.J., Boyken, L., Messer, S.A., Tendolkar, S., Hollis, R.J., Goldstein, B.P., "Effectiveness of anidulafungin in eradicating Candida species in invasive candidiasis" Antimicrob. Agents Chemother, 49, 4795-4797, (2005).

128. Groll, A.H., Mickiene, D., Petraitiene, R., Petraitis, V., Lyman, C.A., Bacher, J.S., Piscitelli, S.C., Walsh, T.J., "Pharmacokinetic and pharmacodynamic modeling of anidulafungin (LY303366): reappraisal of its efficacy in neutropenic animal models of opportunistic mycoses using optimal plasma sampling" Antimicrob. Agents Chemother, 45, 2845-2855, (2001).

129. Roberts, J., Schock, K., Marino, S., Andriole, V.T., "Efficacies of two new antifungal agents, the triazole ravuconazole and the echinocandin LY-303366, in an experimental model of invasive aspergillosis" Antimicrob. Agents Chemother, 44, 3381-3388, (2000). 
130. Krause, D.S., Reinhardt, J., Vazquez, J.A., Reboli, A., Goldstein, B.P., Wible, M., Henkel, T., Anidulafungin Invasive Candidiasis Study Group, "Phase 2, randomized, doseranging study evaluating the safety and efficacy of anidulafungin in invasive candidiasis and candidemia" Antimicrob. Agents Chemother, 48, 2021-2024, (2004).

131. Dowell, J.A., Knebel, W., Ludden, T., Stogniew, M., Krause, D., Henkel, T., "Population pharmacokinetic analysis of anidulafungin, an echinocandin antifungal" J. Clin. Pharmacol, 44, 590-598, (2004). X

132. Triessel, L., Ogundele, A., "Compatibility of anidulafungin with other drugs during simulated Y-site administration" Am. J. Health Syst. Pharm, 62, 834-837, (2005).

Received: 21.11 .2008

Acepted: 11.03.2009 